\title{
Dynamic Plasticity of Axons within a Cutaneous Milieu
}

\author{
Chu Cheng, Gui Fang Guo, Jose A. Martinez, Vandana Singh, and Douglas W. Zochodne \\ Department of Clinical Neurosciences and the Hotchkiss Brain Institute, University of Calgary, Calgary, Alberta, Canada T2N 4N1
}

The skin is a repository of sensory axons immersed within the turnover of epidermal, follicular, and dermal cellular constituents. We show that epidermal and perifollicular axons within intact hairy skin of mice possess a remarkable dynamic plasticity linked to their microenvironment. For example, the majority of epidermal axons express the growth protein GAP43. Unexpectedly, we induced new cutaneous axogenesis by simple and noninvasive hair clipping, a response linked to a series of changes in their cutaneous neighbors. In thy-1 YFP transgenic mice with fluorescent axons, superficial epidermal and perifollicular cells newly acquired YFP, indicating diffuse activation by clipping despite the absence of skin injury. At $48 \mathrm{~h}$ after clipping, this activation was accompanied by a rise in the number of epidermal cells, transient rises in mRNA of Sox2, a marker of follicular stem cells, and a rise in mRNA of glial fibrillary acidic protein, a marker of glial cells. Axons responded with rises in their numbers in the epidermis and around dermal hair follicles. Linking these responses were early, large, and selective rises in hepatic growth factor (HGF) mRNA, with its protein identified in epidermal cells, perifollicular cells, and sensory axons. Moreover, these elements also expressed the HGF receptor c-Met, especially in small caliber sensory neurons. Finally, we identified concurrent rises in Racl activation, a downstream target of ligated c-Met. Together, these results confirm critical linkages between sensory axons and their cutaneous milieu. We believe that the plasticity is provoked by follicularoriginating cutaneous activation with HGF and Rac1 signaling, allowing cross talk and axonal remodeling.

\section{Introduction}

Complex interactions among cutaneous epidermal cells and the axons that innervate the skin may allow appropriate remodeling of both over time and after injury. Several forms of signaling likely underlie these interactions, but what candidates are involved has not been fully explored. One might guess that axons and epidermal stem cells would recapitulate developmental relationships. Neural precursor cells in hair follicles (Fernandes et al., 2004; Toma et al., 2005; Biernaskie et al., 2006, 2009) could contribute to structural plasticity of cutaneous nerve fibers. For example, it may be that epidermal axon growth, as in neurodevelopment, depends on gradients of local growth factors that direct axons toward the surface of the skin or around hair follicles. An important candidate for linking axons and epidermal cells is HGF (hepatic growth factor), originally named scatter factor because of its propensity to induce epithelial cell migration. HGF, signaling through its c-Met tyrosine kinase receptor, is a critical facilitator of wound healing (Yoshida et al., 2003; Chmielowiec et al., 2007). One of the downstream targets of HGF-c-Met involves activation of Rac1. Although not extensively studied in peripheral neurons, HGF has been identified as a neuronal growth factor and its receptors are expressed on neurons (Maina and Klein, 1999; David et al., 2008). An additional

Received June 8, 2010; revised Aug. 28, 2010; accepted Sept. 8, 2010.

The work was supported by operating grants of the Canadian Institutes of Health Research and the Canadian Diabetes Association. D.W.Z. has been supported as a scientist of the Alberta Heritage Foundation for Medical Research. We thank Drs. Dennis $0^{\prime}$ Leary and Todd McLaughlin for providing invaluable assistance in completing the stripe assays.

Correspondence should be addressed to Dr. Douglas W. Zochodne, 168 Heritage Medical Research Building, 3330 Hospital Drive NW, Calgary, Alberta, Canada T2N 4N1. E-mail: dzochodn@ucalgary.ca.

DOI:10.1523/JNEUROSCI.2919-10.2010

Copyright $\odot 2010$ the authors $\quad 0270-6474 / 10 / 3014735-10 \$ 15.00 / 0$ role of HGF is to support Schwann cell proliferation (Krasnoselsky et al., 1994).

Evidence for axonal remodeling in skin has been observed in disorders ranging from HIV infection, diabetes mellitus, and chemical or wax depilation, to frank skin inflammation and wounding (Holland et al., 1997; Herrmann et al., 1999; Lauria et al., 2005; Hendrix and Peters, 2007). These are invasive injuries. For example, depilation approaches remove the full hair shaft from within the epidermis. It is likely, however, that more subtle forms of ongoing axon growth allow maintenance of innervation within a changing organ, the skin. How cutaneous cells and axons collaborate during frank injury or growth is not clear.

In this work, an initial aim was to investigate wound hyperinnervation (Henderson et al., 2006) through approaches that included use of the thy1-YFP mouse, a transgenic model in which a high proportion of axons, including sensory axons that innervate the skin, express the fluorochrome (Feng et al., 2000). The transgene is not known to be expressed in non-neuronal tissues. In the study of wound healing in hairy skin of mice however, we unexpectedly encountered robust axon and cutaneous plasticity in our control experiment-simple skin clipping or shaving without skin wounding. After simple hair clipping, we induced epidermal keratinocyte activation (new thy-1 YFP expression), epidermal proliferation, rises in the expression of follicular stem cell markers, and axon remodeling - all associated with large rises in the expression of HGF and with Racl activation. The present report focuses on this unexpected plasticity as a window on how axons behave within their cutaneous milieu.

\section{Materials and Methods}

Mice. Mice studied were outbred adult male CD-1 mice (25-35 g; Charles River) for the biopsy, clipping immunohistochemistry, and mRNA studies and male B6.Cg-Tg (Thy1-YFPH) ZJrs/J hemizygous (2006, 2007) 


\section{Table 1. Antibodies and dilutions}

PGP9.5,1:1000 (rabbit polyclonal; Cedarlane)
PGP9.5, 1:1000 (guinea pig polyclonal; Abcam)
GAP43,1:500 (rabbit polyclonal; Abcam)
SP,1:1000 (rabbit polyclonal; Serotec)
GFP (FL), 1:100 (rabbit polyclonal; sc-833; Santa Cruz Biotechnology)
GFAP, 1:250 (rabbit polyclonal; DAkocytomation)
SOX2, 1:100 (rabbit polyclonal; Abcam)
SOX9, 1:100 (rabbit polyclonal; Abcam)
HGF, 1:80 (goat anti-mouse; R \& D Systems)
Met (SP260), 1:200 (rabbit polyclonal; Santa Cruz Biotechnology)
NF200, 1:800 (mouse monoclonal; Sigma)
Alexa 488, 1:200 (goat and guinea pig; Invitrogen)
Alexa Fluor 488, 1:200 (donkey anti-goat; Invitrogen)
CY3, 1:100 (sheep anti-mouse; Sigma)
CY3, 1:100 (goat anti-rabbit; Cedarlane)

mice from Jackson Laboratory (31-46 g) for in vivo imaging studies and immunohistochemistry. The protocol was reviewed and approved by the Animal Care Committee, University of Calgary. Hair clipping was performed noninvasively using an electric hair clipper (Oster A5 Cryotech size $40 \mathrm{~mm}$ ). Dorsal thorax skin biopsies were performed immediately after reshaving using a $3 \mathrm{~mm}$ punch (Acu Punch; Acuderm) under halothane or pentobarbital $(65 \mathrm{mg} / \mathrm{kg}$ ) anesthesia. By the $7 \mathrm{~d}$ endpoint (see below), only partial hair regrowth was evident, and the skin was reclipped just before harvesting.

Immunohistochemistry. Skin sections were of 16 or $25 \mu \mathrm{m}$ thickness and antibodies used are listed in Table 1 . The immunohistochemical approach was identical to published techniques from our laboratory (Kennedy and Zochodne, 2005; Brussee et al., 2008). For Sox2, HGF, and Met, we used fresh samples fast frozen in OCT and stored at $-80^{\circ} \mathrm{C}$. Sections were postfixed in precooled acetone (the acetone was precooled at $-20^{\circ} \mathrm{C}$ for $30 \mathrm{~min}$ ), then the slide placed into the acetone at $-20^{\circ} \mathrm{C}$ for $10 \mathrm{~min}$, washed with PBS, and immunostained according to our standard protocol. Images were captured using an Olympus laser scanning confocal microscope equipped with epifluorescence and a Zeiss Axioskope fluorescent microscope. Epidermal and dermal fibers were counted in five adjacent fields of six sections for a total 30 fields per mouse at each time point. Hair follicles with or without PGP9.5-labeled axons were counted in horizontal planes of each section. All analysis was conducted with the examiner blinded to the identity of the samples being studied. For epidermal nuclei, we counted the number of all DAPI-labeled nuclei in five different areas (at $400 \times$ magnification) along the epidermis skin within an arbitrarily fixed grid area $\left(100\right.$ micron $\left.^{2}\right)$ and averaged the counts in three sections/sample ( 15 separate measures per mouse; $n=$ 3-4 mice/time point).

Quantitative real-time PCR. Skin areas for biopsy were first treated with an inactivator of RNase (RNaseZap; Applied Biosystems), then biopsy samples were flash frozen and underwent RNA extraction using Trizol Reagent (Invitrogen). We examined several housekeeping genes for their stability during our interventions and encountered substantial variability in their baseline expression, excepting serpin-1 and ribosomal acidic protein PO, used to confirm the results. Quantitative real-time PCR (qRT-PCR) was performed as reported previously (Cheng et al., 2008). The primer sequences used were designed in Primer Express 2.0 (Applied Biosystems) and are given in Table 2. The unknown samples were compared against the calibrator sample to give relative gene expression using the comparative $\mathrm{C}_{\mathrm{T}}$ method $2^{-\Delta \Delta \mathrm{C}_{\mathrm{T}}}$.

Immunoblots. Back skin biopsy samples of CD1 mice on $\mathrm{d} 0$ (immediately after shaving), $\mathrm{d} 2$, and $\mathrm{d} 7$ were collected and stored at $-80^{\circ} \mathrm{C}$ for immunoblots. For each time point, eight skin biopsy samples from four mice were used and analysis was performed on three separate occasions ( $n=36$ mice in total). Briefly, skin biopsy samples were suspended in lysis buffer (150 mm NaCL, 2 mm EDTA, 50 mm Tris, 1\% NP40, 0.5\% sodium deoxycholate, and $0.2 \%$ SDS, $\mathrm{pH} 7.4$ ) with a protease inhibitor mixture (Roche Applied Science). The samples were homogenized, centrifuged $\left(10,000 \mathrm{rpm}, 30 \mathrm{~min}\right.$ at $\left.4^{\circ} \mathrm{C}\right)$, and the protein concentration of the supernatant was determined using bicinchoninic acid (BCA) assay

\section{Table 2. Primer sequences}

NF200 M F5'-TACAGAAAGCTCCTGGAAGGC-3'
NF200 M R5'-TTATGTGCGTGGATATGGAGG-3'

Tubulinb3M F 5'-AAGGTAGCCGTGTGTGACATCC-3'

Tubulinb3M R 5'-TGCTCCGAGATGCGTTTGA-3'

NGFb M F 5'-TTGCCAAGGACGCAGCTTT-3'

NGFb M R 5'-TGCCTGTACGCCGATCAAA-3'

FGF2 MR F 5' -AGCGACCCACACGTCAAACTAC-3'

FGF2 MR F 5' - CAGCCGTCCATCTTCCTTCATA-3'

SPprecM F5'-AAGACCCAAGCCTCAGCAGTTC-3'

SPprecM R5'-TGGCCATGTCCATAAAGAGCC- $3^{\prime}$

BDNF RM F5'-GGAGGAATTTCTGAGTGGCCA-3' RAT AND MOUSE

BDNF RM R3' -ACACATCATTCCAGAGCCTGCT-3' RAT AND MOUSE

BMP7 MR F 5' -CAAAGAACCAAGAGGCCCTGA-3'

BMP7 MR R 5' -TCTCGGAAGCTGACGTACAGCT-3'

BMP4 MRH F 5' -CCGAATGCTGATGGTCGTTT-3'

BMP4 MRH R $5^{\prime}$-CCGAATGCTGATGGTCGTTT-3'

BMP2 MRH R 5' -CCACAAACGAGAAAAGCGTCA-3'

BMP2 MRH R 5' -ACCCCACATCACTGAAGTCCAC- $3^{\prime}$

Keratin 15 M F 5'-AGGAGGTGGCGTCTAACACAGA-3'

Keratin 15 M R 5' -CATGCTGAGCTGAGACTGCAAC-3'

SLUGM F 5' -TGATGCCCAGTCTAGGAAATCG-3'

SLUGM R $55^{\prime}$-GCCACAGATCTTGCAGACACAA-3'

Serpinb1b M F 5'-ACACCCTCTTCACCTTGGAGCT-3'

Serpinb1b M R 5' -CCATGGCCAAGGAAGAAGAAAT-3'

RPLPOF 5'-AAGAACACCATGATGCGCAAG-3'

RPLPO R 5'-TTGGTGAACACGAAGCCCA-3'

Pax2 MR F 5'-TGGACAGTTTGCGGAAGCA-3'

Pax2 MR R 5' -TCTGATGCCTGGAAGACATCG-3'

HGF RM F5'-AACACAGCTTTTTGCCTTCGAG-3'

HGF RM R5' -CTGGATTGCTTGTGAAACACCA-3'

RPLPO M F 5'-AAGAACACCATGATGCGCAAG-3'

RPLPOM F 5'-TTGGTGAACACGAAGCCCA-3'

EGF M F 5'-TCCTGGACAAACGGCTCTTCT-3'

EGF M R 5' -TGATGCCTGATAAGACGGACG-3'

SOX9 MR F 5' -CCAACATTGAGACCTTCGACGT-3'

SOX9 MR R 5' -ATGCCGTAACTGCCAGTGTAGG-3'

Neurod1 M F5' -AAAGCCCCCTAACTGACTGCA-3'

Neurod1 M R5'-TCAAACTCGGCGGATGGTT-3'

Neurod2 M F5'-AGCTGTCCAAGATCGAGACCCT-3'

Neurod2 M R'-CCTTGCACAGAGTCTGCACGTA-3'

$M$, Amplifies a mouse sequence; $R$, amplifies a rat sequence; $H$, amplifies a human sequence; $M R$ and $R M$, amplifies both mouse and rat sequences.

(BCA protein assay kit; Thermo Scientific). Equal amount of protein (30 $\mu \mathrm{g}$ for each time point) were resuspended in $2 \times$ Laemmli sample buffer (Bio-Rad) and boiled for $5 \mathrm{~min}$. Afterwards, the samples were ready for electrophoresis on a $12 \%$ SDS-PAGE gel at 120 V. Samples were then transferred on to nitrocellulose and immunodetected with the same methods as mentioned for activated Racl (see below), except that the primary antibody was rabbit polyclonal to Sox 2 (1:500; Abcam) and the secondary antibody was goat anti-rabbit HRP (1:1000; Santa Cruz Biotechnology). Western Lighting Plus (PerkinElmer) was used to detect proteins immobilized on the nitrocellulose membrane. The blots were then scanned and analyzed using ImageJ according to the National Institutes of Health online instructions.

Pull-down assay of activated Rac1. Racl activation was measured using an assay kit (Millipore). CD1 mice back-skin biopsy samples were stored at $-80^{\circ} \mathrm{C}$. For protein extract preparation, $0.5 \mathrm{ml}$ of ice-cold $1 \times \mathrm{MLB}$ $\left(\mathrm{Mg}^{2+}\right.$ lysis/wash buffer) with Protease Inhibitor Cocktail (Roche) was added to each sample. Sample homogenates were spun at 132,000 rpm for $10 \mathrm{~min}$ and the supernatants were saved for active Racl pull-down assay and for total Racl content. Protein concentrations were measured with the BCA protein assay kit to allow equal loading of protein. For each sample, $15 \mu \mathrm{l}(15 \mu \mathrm{g})$ of Rac/cdc42 assay reagent (agarose) was added and the sample incubated $60 \mathrm{~min}$ at $4^{\circ} \mathrm{C}$ with gentle agitation. Positive and negative controls were prepared according to assay protocol. After incubation, we collected the agarose beads and washed them three times 

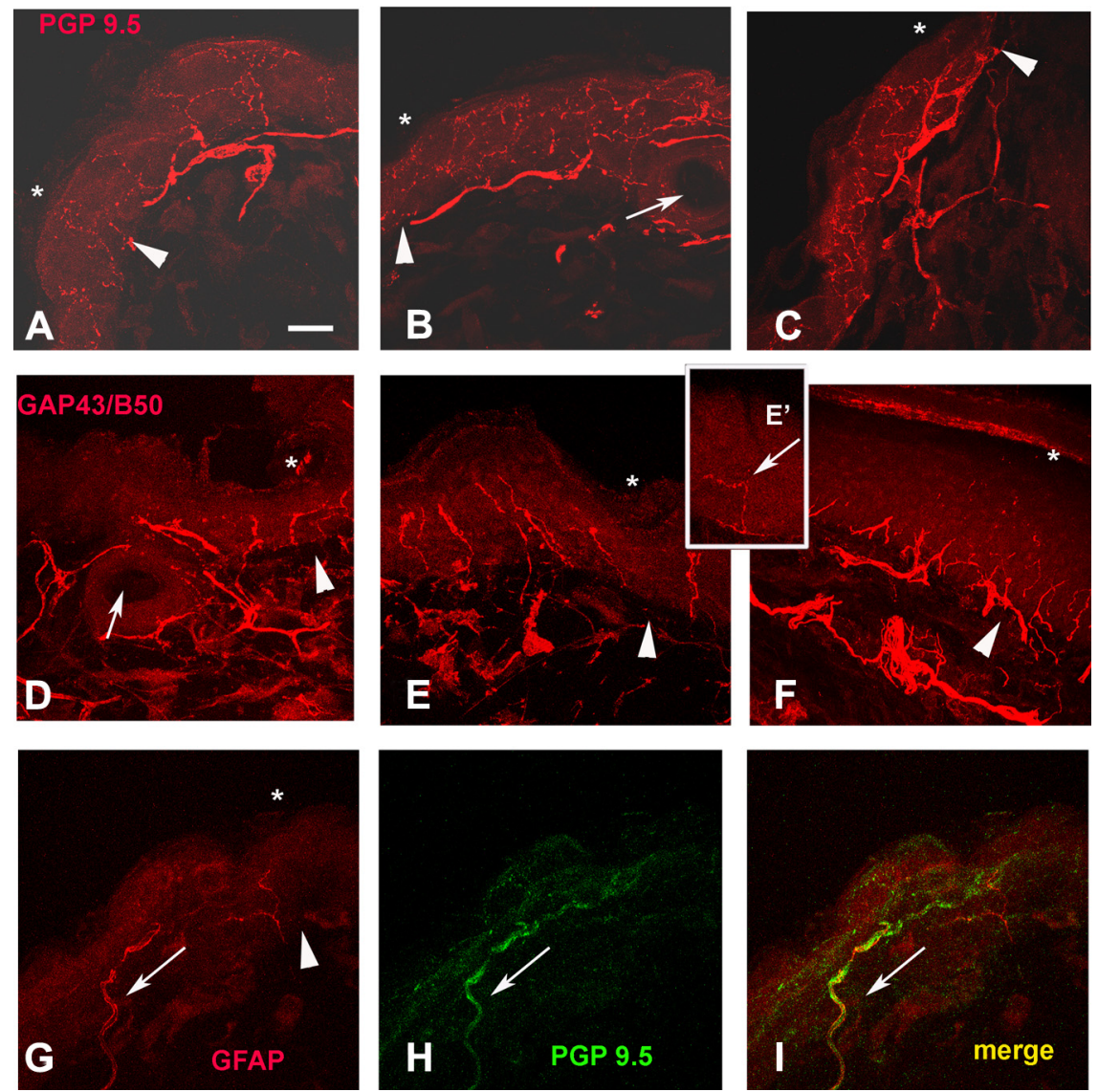

Figure 1. Intact skin has evidence of inherent plasticity. $\boldsymbol{A}-\boldsymbol{C}$, Images of dorsal trunk skin of the mouse labeled with antibodies directed against PGP9.5, which is expressed in all dermal and epidermal fibers. Note the large caliber nerve bundles within the dermis that ramify outward into the epidermis. The epidermal profiles are highly tortuous. The arrow points to a dermal hair follicle, just below the epidermis (central shaft area is dark), that is associated with axons. $\boldsymbol{D}-\boldsymbol{F}$, Axons labeled for GAP43/B50, a regeneration-related growth molecule, are observed in large numbers of dermal (including perifollicular axons; $\boldsymbol{D}$, arrow) and epidermal axons indicating an ongoing plastic, regenerative phenotype. Note the abrupt change in trajectory in a GAP43/B50labeled epidermal axon $\left(\boldsymbol{E}^{\prime}\right.$, arrow). $\mathbf{G}-\boldsymbol{I}$, Dermal axons (PGP9.5) are closely accompanied (arrows) by fine activated glial cell processes (GFAP), indicating a close and potentially supportive role for axon regeneration. Asterisks indicates outer surface of the skin and arrowheads indicate the dermal-epidermal junction. Scale bar, $20 \mu \mathrm{m}$.

with $1 \times$ MLB. Following washing, the agarose beads were resuspended in $17 \mu \mathrm{l}$ of $2 \times$ Laemmli reducing sample buffer and boiled for $5 \mathrm{~min}$. Samples were run on a $12 \%$ SDS gel and transferred to a nitrocellulose membrane, blocked in 5\% nonfat dry milk in TBS-T, and incubated with anti-Racl antibody (1:1000) overnight. The secondary antibody used for this assay was goat anti-mouse HRP (1:2000; $1.5 \mathrm{~h}$ at room temperature). Western Lighting Plus (PerkinElmer) was used to detect proteins immobilized on nitrocellulose membrane. The activation assay was repeated three times and at three different time points and contained positive and a negative controls.

Stripe assay for axon guidance. Analysis of sensory neuron outgrowth was analyzed using a modification of the protein stripe assay, as reported previously (Rashid et al., 2005; Lim et al., 2008) and was carried out, with permission, in the O'Leary laboratory. Neonatal DRG neurons from anesthetized (Nembutol sodium, $50 \mathrm{mg} / \mathrm{kg}$ ) postnatal day $0-8 \mathrm{CD} 1$ and C57BL/6 mice (Charles River and Jackson Laboratories, respectively) were harvested, dissociated in trypsin, triturated, and placed into single cell suspension (two to three mice per harvest) on $18 \mathrm{~mm}$ coverslips on which stripes had been applied. Stripes containing HGF $(3.3 \mathrm{ng} / \mathrm{ml}$ in HBSS) and a fluorochrome marker (rhodamine B isothiocyanate dextran 10S, R8881 at $150 \mu \mathrm{g} / \mathrm{ml}$; Sigma) were applied on coverslips precoated with poly-L-lysine and subsequently coated with laminin $(20 \mu \mathrm{g} / \mathrm{ml}$ in HBSS). Control stripes were created identically without HGF. Neurons were grown until d 3 [neurobasal media (Invitrogen), glucose (2 mM), glutamine (2 mM), B27 supplement without insulin (Invitrogen), HEPES
(10 mM), sodium pyruvate (1 mM), forskolin (6 $\mu \mathrm{M})$, and penicillin/streptomycin], then stained with carboxyfluorescein diacetate, succinimidyl ester (fluorescent vital dye, C1157; Molecular Probes). Slides were immediately imaged and captured on an Olympus BX61 microscope with a Retiga 2000DC camera and MetaMorph Advanced 7.7 software. We used a $10 \times$ objective and neurons were analyzed offline. Discrete neurons were counted that were present on a stripe or had a primary branch that entered a stripe. In a separate analysis, neurite terminals that ended on a stripe or adjacent nonstripe were counted. Assays and analysis were repeated on three separate occasions for each of the HGF and control preparations.

Analysis. Data were calculated as mean \pm SEM. Data were analyzed by one-way ANOVA with Tukey's multiple-comparison post hoc test or using one- or two-tailed Student's $t$ test comparisons (unless otherwise stated). In all tests, statistical significance was set at $\alpha=0.05$.

\section{Results}

\section{Epidermal axons possess}

intrinsic plasticity

We first asked whether cutaneous axons, including epidermal axons of intact unaltered adult skin, might display features of a regenerating, plastic phenotype. In normal adult outbred CD-1 mice, we observed the expected epidermal, dermal, and perifollicular innervation in biopsies of dorsal trunk skin using the panaxonal marker PGP9.5. In particular, epidermal axons were highly tortuous and ramified throughout the superficial and deep layers, as described previously (Kennedy and Wendelschafer-Crabb, 1993) (Fig. 1A-C). In concurrent samples labeled for the growth protein GAP43/B50, a substantial fraction of the axon population, both in the dermis and epidermis, expressed the protein. This colocalization confirmed findings by Fantini and Johansson (1992) and was quantitated. In the epidermis, the proportion of GAP43/B50-labeled axons was 72\% of all outwardly directed axons (Fig. 1D-F). Intact skin also expressed GAP43/ B50 mRNA as well as other neural-specific mRNAs required for axon growth and structure, including $\beta$ III tubulin and Nf200, the heavy subunit of neurofilament. There was also expression of glial fibrillary acidic protein (GFAP) mRNA within intact skin; GFAP was identified by immunohistochemistry in glial processes closely apposed to subepidermal dermal axons, including those of large caliber (Fig. 1G-I). GFAP may be expressed by Schwann cells (SCs) normally associated with unmyelinated axons, but is also prominent in activated SCs during regenerative outgrowth (Cheng and Zochodne, 2002; McDonald et al., 2006). Together, these findings indicated that axons of intact skin had the phenotype and microenvironment capable of supporting regenerative plasticity.

\section{Cutaneous thy-1 YFP activation in response to noninvasive hair clipping}

We identified a wave of unexpected cutaneous plasticity after simple hair clipping alone (control experiment) during a study 

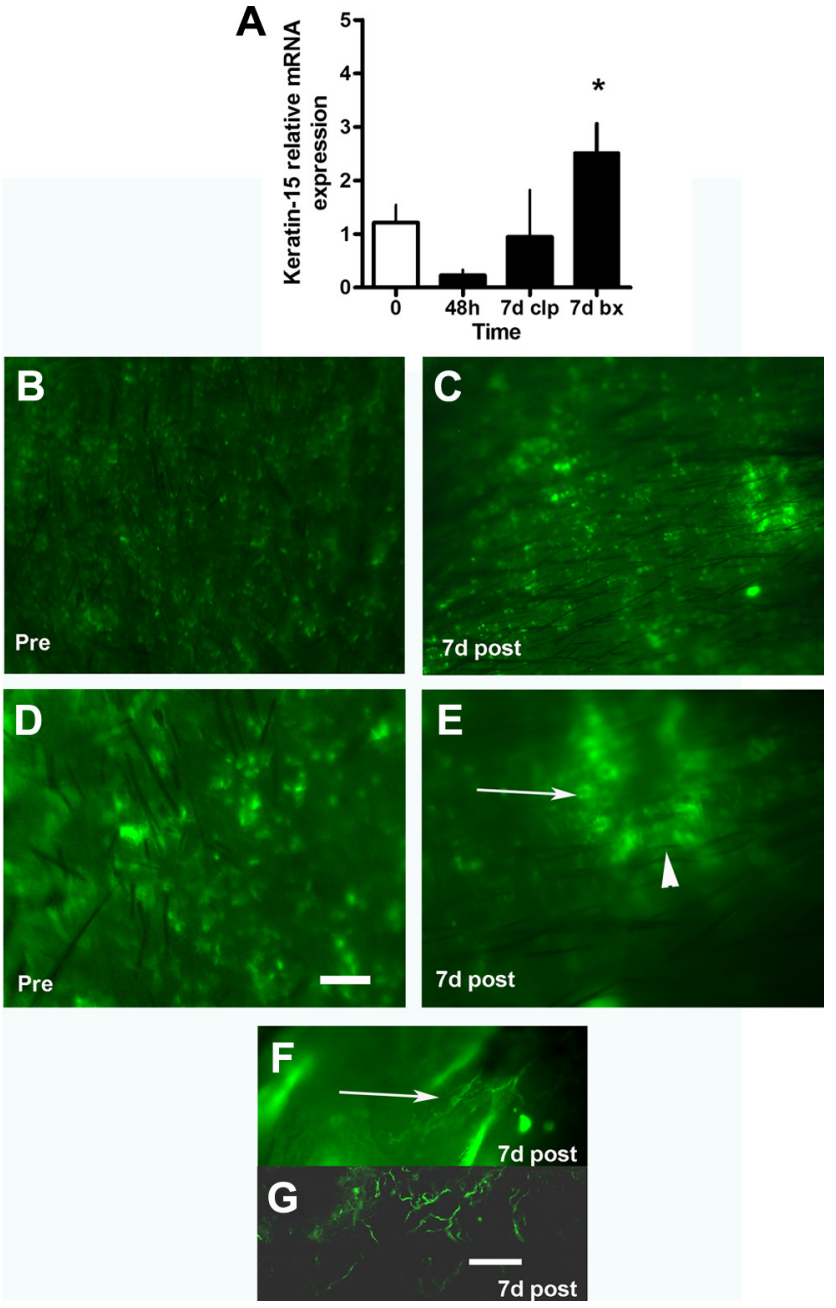

Figure 2. Hair clipping alters thy-1 YFP expression in perifollicular cells without damaging the skin. $\boldsymbol{A}$, Keratin-15 mRNA expression is unchanged or reduced, rather than elevated, following noninvasive skin clipping ( $48 \mathrm{~h}, 7 \mathrm{~d} \mathrm{clp}$ ), indicating that deeper epidermal layers were not injured. In contrast, skin having undergone an invasive biopsy wound (7 d bx) had a rise in keratin-15 expression ( ${ }^{*} p=0.05$, ANOVA). $\boldsymbol{B}-\boldsymbol{E}$, In percutaneous images from live mice, the same area of skin in the same mouse is seen by epifluorescence before $(\boldsymbol{B}, \boldsymbol{D})$ and after $(\boldsymbol{C}, \boldsymbol{E})$ clipping. Note the donut shaped ( $\boldsymbol{E}$, arrow; hair shaft is in the center) intense areas of YFP expression $7 \mathrm{~d}$ following a single episode of hair clipping at low $(\boldsymbol{C})$ and high $(\boldsymbol{E})$ magnification. The expression is often diffuse and not confined to discrete profiles (arrowhead). Scale bar: $\boldsymbol{D}, \boldsymbol{E}$ $200 \mu \mathrm{m} ; \boldsymbol{B}, \boldsymbol{C}, 500 \mu \mathrm{M} . \boldsymbol{F}, \boldsymbol{G}$, Identification of YFP-expressing axons in the skin is shown using conventional epifluorescence $(\boldsymbol{F})$ and confocal serial imaging $(\boldsymbol{G})$ of the skin in live mice $7 \mathrm{~d}$ following shaving. Scale bar, $100 \mu \mathrm{m}$.

initially aimed at investigating skin wounds. Simple hair clipping was not associated with clinical or histological evidence of actual skin injury or penetration and a truncated hair shaft still emerged from the skin. To confirm the absence of direct deeper epidermal injury after hair clipping, we measured skin samples for keratin-15 mRNA, a marker of deep-layer epithelial cell plasticity (Whitbread and Powell, 1998). Although $\sim 2.5$-fold rises in keratin-15 mRNA were observed $7 \mathrm{~d}$ after an invasive punch skin biopsy, clipping alone was not associated with rises in its expression at $48 \mathrm{~h}$ or $7 \mathrm{~d}$ (Fig. $2 \mathrm{~A}$ ).

There was evidence of a striking change in superficial epidermal cell behavior after hair clipping. This was evidenced in mice with a thy-1-linked YFP transgene, in which YFP is expressed in sensory axons but not normally in other cell types (Feng et al., 2000). In fluorescent images of living mouse back skin, not previously shaved, punctuate low-intensity YFP fluorescence could be observed, identifying probable outwardly directed dermal axon bundles (Fig. $2 \mathrm{~B}, \mathrm{D}$ ). After hair clipping, by $48 \mathrm{~h}$, there was a change in this pattern of fluorescence with a rise in local diffuse YFP fluorescence in the epidermis, a keratinocyte activation response described previously (Pan and Sanes, 2004) following invasive injuries and also seen in our invasively biopsied specimens (data not shown). This response was distinguished from autofluorescence, which was not observed (excepting in hair shafts) within the skin of wild-type mice immediately after shaving. The novel epidermal YFP fluorescence (Fig. 2C,E) that was expressed later included fluorescence of skin axons and was persistent 7 and $14 \mathrm{~d}$ following clipping. A prominent site of new YFP fluorescence was observed in rings around hair follicles. In additional work, we used live animal confocal fluorescent imaging through serial depths of the skin. These images confirmed that YFP axon profiles contributed, along with keratinocytes, to the rise in skin fluorescence after shaving (Fig. $2 F, G$ ). Overall, our findings indicate a diffuse change in superficial epidermal cell behavior, with new acquisition of the thy-1-linked YFP reporter and prominent perifollicular signal acquisition.

\section{Activation of a cutaneous proliferative state}

That noninvasive hair-clipping-generated epidermal plasticity was further shown by a rise in superficial epidermal cell nuclear density, counted using DAPI nuclear labeling at $48 \mathrm{~h}$ (Fig. 3A-E). A control (sham) intervention, applying the clipper to an identical area of skin with similar force, but without powering the clipper blades, did not alter superficial epidermal cell nuclear density. Thus, this response was specifically associated with truncation of the hair shaft, not skin rubbing or minor trauma.

Since skin-derived precursor cells have been shown to differentiate into glial cell populations that support axogenesis, we next asked whether our noninvasive stimulus might be sufficient to activate this population of cells (Hong and Saint-Jeannet, 2005). Clipping was associated with a large rise in GFAP mRNA, a marker of glial cells including Schwann cells (Fig. 3F). To address cutaneous stem cell populations, we chose the following markers for qRT-PCR analysis of mRNA in skin: Sox2, Sox 9, Slug, Neurod1, Neurod2, and Pax 2. Although there were trends toward rises in Sox9, Slug, Pax2, Neurod1, and Neurod2, results were inconsistent (supplemental Fig. 2A,E,F,G, available at www. jneurosci.org as supplemental material). Sox 9 was located in perifollicular cells, both inner and outer, along the hair shaft (supplemental Fig. $2 B-D$, available at www.jneurosci.org as supplemental material). A robust rise in Sox 2 mRNA of 15-fold was identified (Fig. $3 G$ ). Sox 2 was localized to a ring, largely outer, of perifollicular cells (Fig. $3 H, I$ ). Immunoblot analysis confirmed the presence of Sox 2 protein in skin samples. Despite the rise in Sox 2 mRNA, we did not confirm a rise in overall protein levels over the same time period (Fig. $3 J$ ). Together, the findings identified evidence for plasticity in response to our intervention that accompanied changes in axon behavior.

\section{Axogenesis accompanies cutaneous plasticity}

Concurrent with these observations on epidermal and follicular plasticity, we identified evidence of enhanced axon plasticity following our noninvasive intervention. We observed a large but transient rise in the expression of mRNA levels of the axon protein Nf200 (Fig. 4A). At $48 \mathrm{~h}$ following hair clipping, mRNA levels of Nf200 were more than tenfold higher than that of controls, compatible with a rise in its local axon synthesis (Piper and Holt, 2004). Neurofilament is specifically expressed in axons, but is not specific with respect to axon type since small caliber neu- 

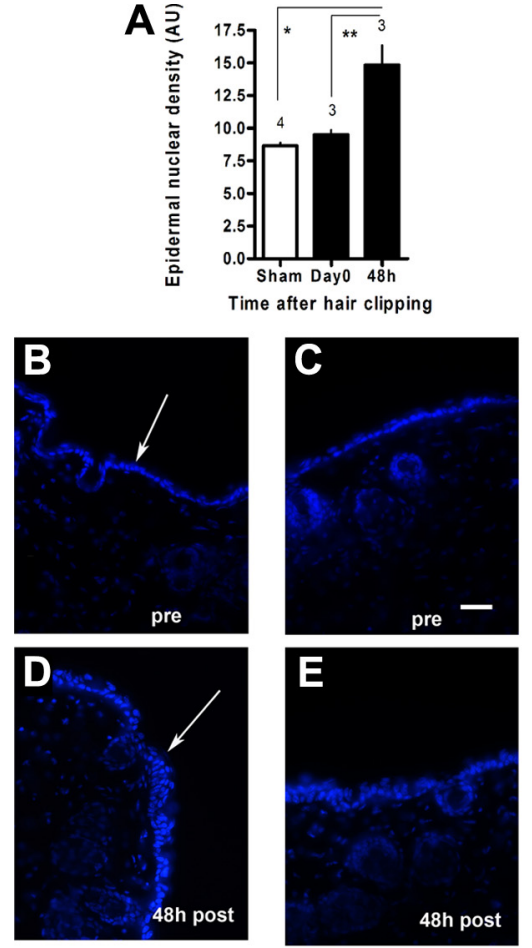

$\mathbf{F}$

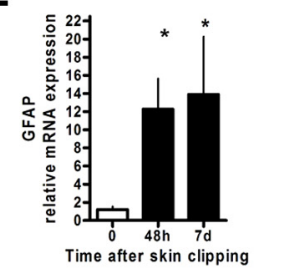

G

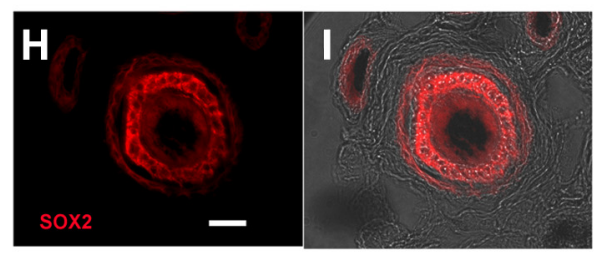

$\mathbf{J}$

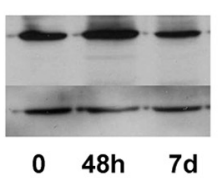

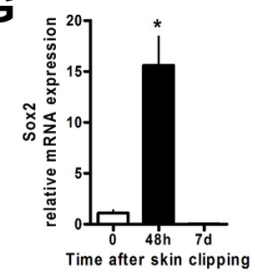

Sox2

actin

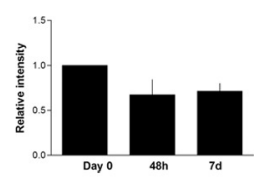

Figure 3. Cutaneous plasticity develops rapidly following noninvasive hair clipping. $A$, Density of epidermal nuclei per unit area in the epidermis. There is a significant rise in epidermal nuclear density $48 \mathrm{~h}$ following hair clipping compared with a sham intervention $\left({ }^{*} p<0.01\right)$ or with $\mathrm{d} 0\left({ }^{* *} p<0.01\right)$. Sham clipping involved applying the clipper to the skin without powering the blades (one-way ANOVA, $p=0.002$; post hoc Tukey test, $n=3$ on d $0, n=3$ at $48 \mathrm{~h}, n=4$ for sham). $\boldsymbol{B}-\boldsymbol{E}$, Examples of epidermal nuclear labeling ( $\boldsymbol{B}$ and $\boldsymbol{C}$, without previous clipping; $\boldsymbol{D}$ and $\boldsymbol{E}$, $48 \mathrm{~h}$ following clipping). The arrows indicate epidermal nuclear labeling and the epidermis faces upward. $\boldsymbol{F}, \boldsymbol{G}$, Clipping was also associated with rises in mRNA levels of GFAP expressed in skin glial cells and in mRNA of Sox2 (G; * ${ }^{*}$ ne-way ANOVA, $p=0.0002$; posthoc Tukey $48 \mathrm{~h}$ vs $\mathrm{d} 0, p<0.05 ; n=5$ at $\mathrm{d} 0$ and $7, n=5$ at $48 \mathrm{~h}$ ), an epidermal stem cell marker $\left(\boldsymbol{F}\right.$; ${ }^{*}$ one-way ANOVA, $p=0.036$; post hoc Tukey d 7 vs $\mathrm{d} 0, p<0.05 ; n=10$ at d $0, n=6$ at $48 \mathrm{~h}$; $n=7$ at d 7). $\boldsymbol{H}, \boldsymbol{I}$, Sox2 was expressed in perifollicular cells, surrounding hair shafts (I, with transmitted light). $\boldsymbol{J}$, Sox2 expression by immunoblot as indicated, compared with actin loading controls. There was no significant change in its overall protein expression at $48 \mathrm{~h}$ or $7 \mathrm{~d}$ after skin hair clipping. Scale bars, $50 \mu \mathrm{m}$.

rons nonetheless do express lower levels of the protein. By $7 \mathrm{~d}$, the levels had declined below those of intact, unclipped skin.

Axon investment of the epidermis was analyzed by immunostaining cutaneous sections with PGP9.5, a panaxonal marker. At $48 \mathrm{~h}$ after clipping, the numbers and density of outgrowing epidermal axons, oriented vertically to the skin surface, was unchanged in samples from previously shaved skin. By $7 \mathrm{~d}$, however, there were rises in the numbers and density of epidermal PGP9.5labeled axons (Fig. 4B,C,F). Together, these findings indicated that simple hair clipping had signaled axon remodeling and a growth response within the epidermis.

Since the only physical alteration to skin generated by clipping was that of obvious though incomplete hair shaft truncation, we next measured the axonal investment of hair follicles, also labeled by PGP9.5. Pelage hair follicles, as studied here, are all normally innervated circumferentially at two different locations, termed follicular network (FN) A at the dermal epidermal junction and FNB, a more organized network around the isthmus of the hair follicle below the sebaceous gland (Botchkarev et al., 1997; Hendrix et al., 2008). We identified the proportion of hair follicle profiles in which the plane of section, largely transverse, included an axon plexus, usually the deeper FNB plexus (Fig. $4 D, E, G$ ). Using six separate sections that sampled both the epidermis and dermis for each biopsy ( $3 \mathrm{~mm}$ punch), a mean of $12 \%$ of dermal follicular profiles had circumferential axons in their plane of section. After clipping, there was a progressive rise ( $24 \%$ by $7 \mathrm{~d})$ in

the proportion of hair follicle profiles with axons in their plane of section. These findings indicated folliculocentric axon remodeling, rendering a more widespread distribution of axons along each hair shaft (Fig. $4 \mathrm{H}-\mathrm{O}$ ).

\section{Rises in HGF expression accompany axon and cutaneous plasticity}

To examine the features of the microenvironment of clipped skin that might promote both cutaneous plasticity and axonogenesis, we examined skin samples for early expressed mRNAs. At $48 \mathrm{~h}$ after clipping, there were relative declines, rather than rises, in mRNAs for BMP2, BMP4, BMP7, FGF2, and NGF $\beta$, all growth factor candidates that might alter axogenesis. mRNA for BDNF was not identified in normal or clipped skin at these time points (supplemental Fig. 3, available at www.jneurosci.org as supplemental material). By $7 \mathrm{~d}$, when epidermal innervation had already changed, there was a two-fold relative rise in FGF2 mRNA, whereas BMP2, BMP4, and BMP7 mRNA were unchanged and NGF $\beta$ mRNA remained below the levels of intact skin. In contrast to these unimpressive changes, we observed large rises in mRNA levels of HGF and epidermal growth factor (EGF) by more than tenfold by $48 \mathrm{~h}$ after simple hair clipping (Fig. 5H). We used immunohistochemistry to localize the source of HGF in skin, a strong candidate for supporting plasticity in skin cells, precursor cells, and axons (Fig. 5I-O). HGF was expressed in most dorsal root ganglia sensory neurons, as previously reported (Hashimoto et al., 2001), and colocalized within neurons with a heavy subunit neurofilament marker. In the skin, HGF was identified in the subdermal axon plexus, including perifollicular axons, in perifollicular and epidermal cells. Consistent with the mRNA results, the intensity of epidermal HGF expression appeared to increase after injury, although this was not quantitated. The HGF receptor c-Met had differing localization than that of the ligand (Fig. 5A-G). c-Met was found predominantly in smaller sensory neurons, and labeled small caliber fibers in sciatic nerve. In the skin, c-Met was in axons of dermal nerve fiber bundles, and was also identified in perifollicular and epidermal keratinocyte cells.

To confirm previous work suggesting a guidance and trophic role for HGF in supporting sensory neurons (Sanford et al., 2008), we performed a stripe guidance assay using harvested neonatal sensory neurons, as previously described (Rashid et al., 2005; Lim et al., 2008) (supplemental methods, available at www. jneurosci.org as supplemental material). In this assay, harvested neurons are provided a choice of substrate stripes to deposit on and to send their neurite branches into. Neuron and neurite behavior were compared between HGF layered stripes and adjacent untreated stripes of similar width and further compared with identical assays lacking HGF on the stripes. These studies confirmed that sensory neurons were more likely to terminate their branches on HGF stripes and to send their primary neurite 

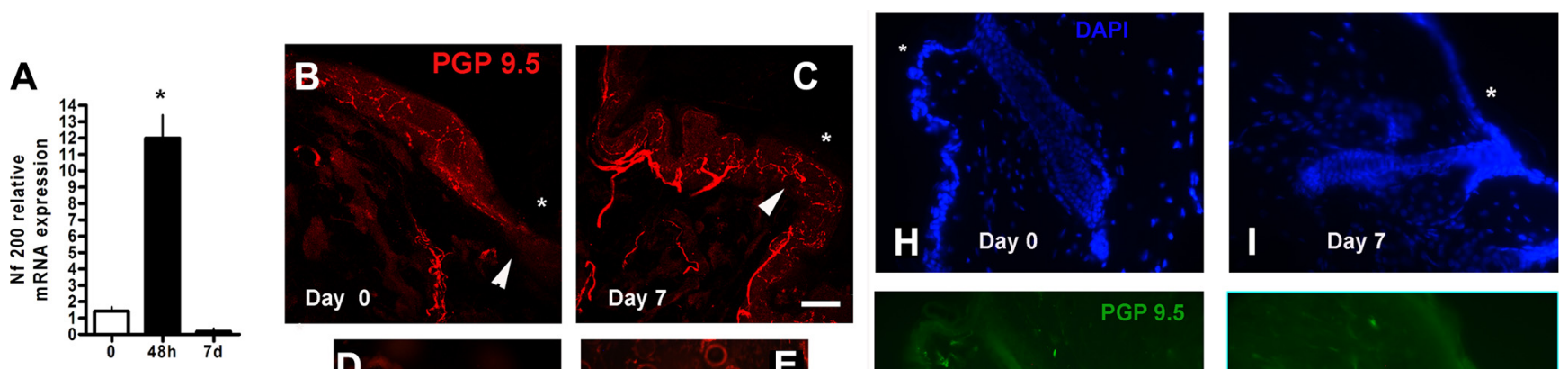

Time after hair clipping
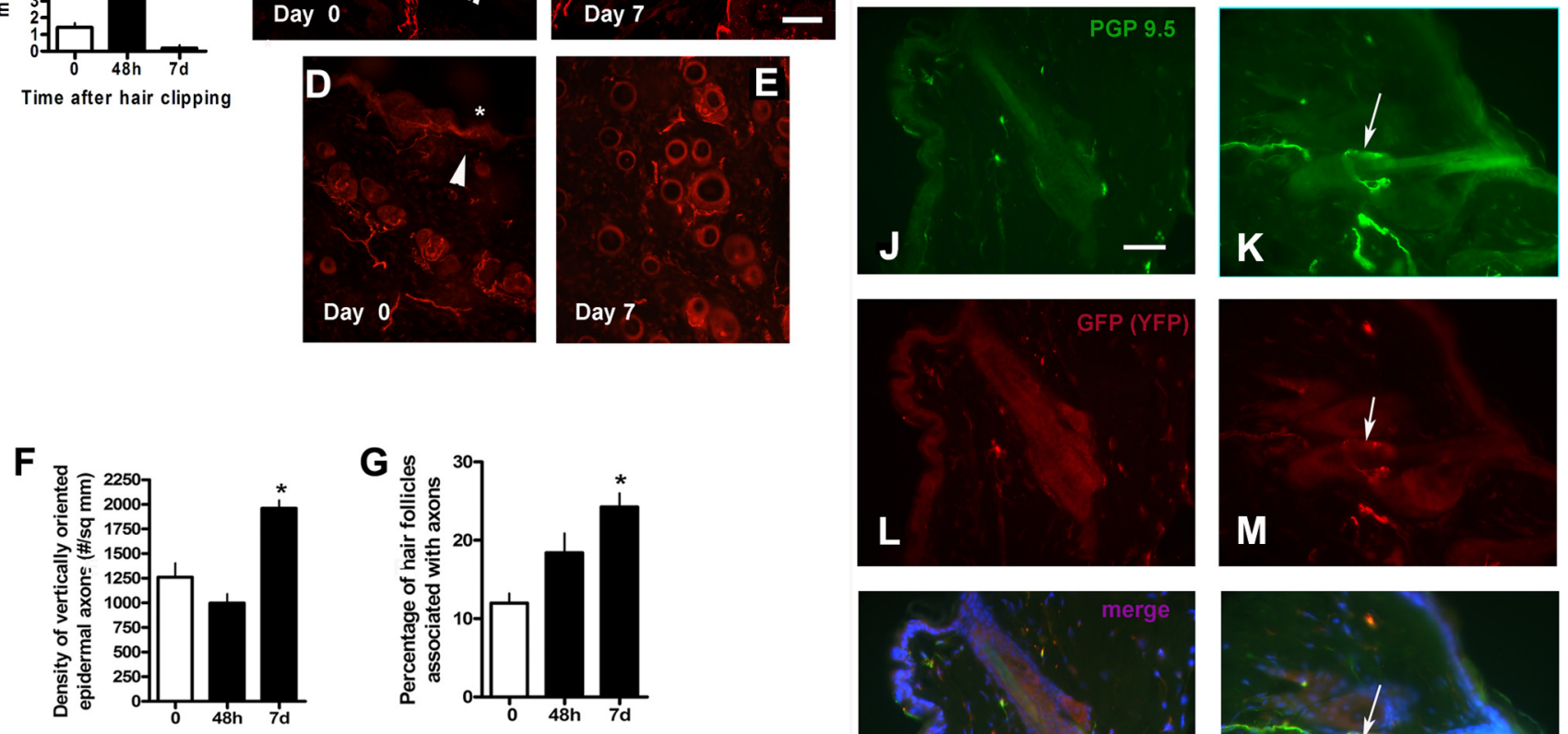

Time after hair clipping
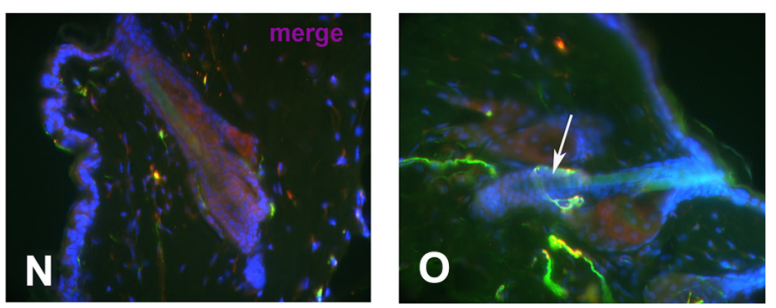

Figure 4. Cutaneous plasticity is accompanied by axogenesis. $A$, There were early (48 h) rises in neurofilament heavy unit (Nf200) mRNA (A; ${ }^{*}$ one-way ANOVA, $p<0.0001 ;$; post hoc Tukey's $t$ test 0 vs $48 \mathrm{~h} ; p<0.001 ; n=10$ at d $0, n=6$ at $48 \mathrm{~h}, n=4$ at d 7), not observed at the later time point. $\boldsymbol{B}$ - $\boldsymbol{E}$, Representative sections of dorsal cutaneous skin showing rises in epidermal innervation $(\boldsymbol{B}, \boldsymbol{C})$ and perifollicular innervation $(\boldsymbol{D}, \boldsymbol{E})$ in controls $(\boldsymbol{B}, \boldsymbol{D})$ and at $7 \mathrm{~d}(\boldsymbol{C}, \boldsymbol{E})$ following simple hair clipping (red, axons labeled with antibody directed toward PGP9.5, epidermis is directed upward; *outer surface of skin; arrowhead, dermal-epidermal junction). Scale bar: $\boldsymbol{B}, \boldsymbol{C}, 20 \mu \mathrm{m} ; \mathbf{D}, \boldsymbol{E}, 100 \mu \mathrm{m}$. $\boldsymbol{F}, \boldsymbol{G}$, Data showing rises in the density of epidermal vertically oriented axons $\left(\boldsymbol{F} ;{ }^{*}\right.$ one-way ANOVA, $p=0.0004 ;$ post hoc Tukey's test d 0 vs 7; $p<0.01 ; n=4$ for each group) and the percentage of perifollicular axons (G; * ${ }^{*}$ ne-way ANOVA, $p=0.0016 ; p$ ost hoc Tukey's test $d 0$ vs $7 ; p<$ $0.01 ; n=4$ for $\mathrm{d} 0$ and $7 ; n=5$ for $48 \mathrm{~h}$ ) after hair clipping. $\boldsymbol{H}-\mathbf{0}$, Images of dorsal cutaneous skin in mice with a thy-1YFP transgene. The images are triple labeled with DAPI to highlight follicular cell nuclei $(\boldsymbol{H}, \boldsymbol{I}$, blue), PGP9.5 to identify axons $(\boldsymbol{J}, \boldsymbol{K}$, green) and anti-GFP (YFP) to enhance the transgene YFP expression $(\boldsymbol{L}, \boldsymbol{M}$, red) and merged $(\boldsymbol{N}, \boldsymbol{O})$. The images are sections through the epidermis and dermis in the plane of a telogen hair follicle either immediately after hair clipping $(\boldsymbol{H}, \boldsymbol{J}, \boldsymbol{L}, \boldsymbol{N}, \mathrm{d} 0)$ or $7 \mathrm{~d}$ following hair clipping in an early anagen phase $(\boldsymbol{I}, \boldsymbol{K}, \boldsymbol{M}, \mathbf{O})$. Clipping left a short shaft of hair in place and did not damage the skin. Note the enhanced innervation of the perifollicular area (arrow points to a perifollicular axon) confirmed to be axons using anti-GFP (YFP) and PGP9.5.

*, Outer surface of skin. Scale bar, $50 \mu \mathrm{m}$.

branches into HGF stripes (supplemental Fig. 4, available at www.jneurosci.org as supplemental material). In additional work, we noted that neurons (cell bodies) were more likely to seed on HGF stripes than on nonstripes, whereas control preparations without HGF did not have preferential seeding (60.9 \pm $1.9 \%$ on HGF stripes compared with $46.8 \pm 3.4 \%$ on control stripes; $p=0.02$, Student's unpaired $t$ test).

Overall, these findings identified the ligand and receptor for bidirectional signaling between epidermal, dermal, and follicular cells with axons and confirmed that HGF is an important molecule in influencing the behavior of sensory neuron branches.

\section{Activation of Racl accompanies axon and} cutaneous remodeling

To evaluate potential downstream second messengers of growth factors, specifically HGF-c-Met signaling after shaving, we analyzed skin samples for activated Rac-1. Rac-1 operates downstream of c-Met-PI3K, and is important for the cytoskeletal reorganization of actin (Zhang and Vande Woude, 2003). We did not observe a change in overall Rac-1 expression after hair clipping, but there was a large rise in activated Rac-1 expression at $48 \mathrm{~h}$ following clipping (Fig. 6). By d 7, activated Rac-1 levels had declined but remained above baseline values. These findings identified an early rise in a signaling mechanism, used by HGFc-Met, but also other ligand-receptors capable of linking early dynamic behavior among axons, epidermal cells, and follicular cells.

\section{Discussion}

Dynamic plasticity of individual cutaneous axons is difficult to demonstrate in vivo. Ideally, an individually resolved epidermal axon during live imaging would be tracked over several days, a challenging task to accomplish during axon growth, particularly as axon branches project in and out of the focal plane. Despite this current inability to track axons in real time, many features of the appearance of axons in sections of the dermis and epidermis strongly suggest robust and ongoing normal plasticity. Axon trajectories are tortuous and penetrate through layers of keratino- 

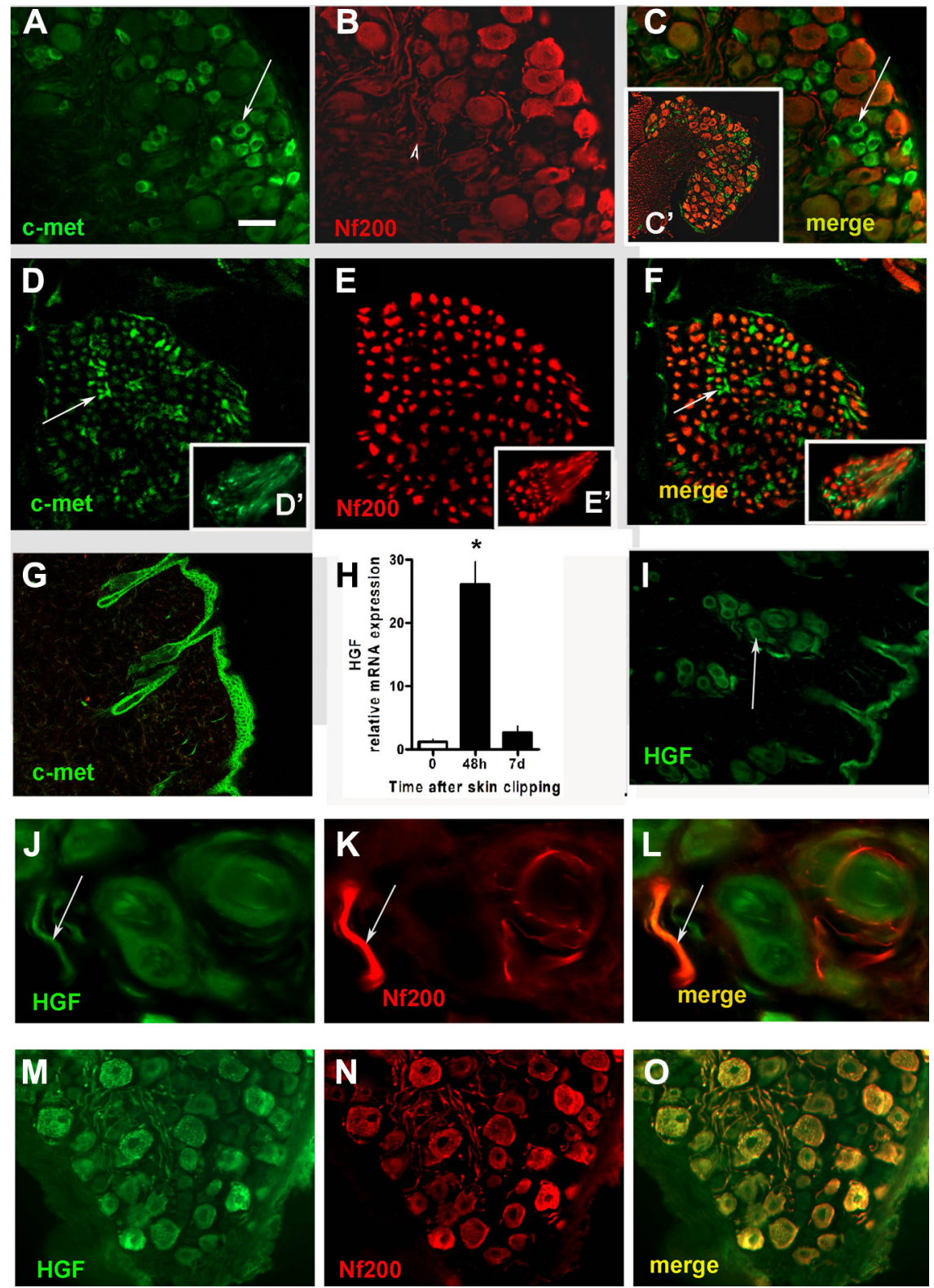

Figure 5. HGF ligand and receptor are expressed in sensory neurons, axons, epidermal cells, and follicular cells. $\mathbf{A}-\mathbf{G}$, Immunohistochemistry illustrating expression of $\mathrm{c}-\mathrm{Met}$, the HGF receptor in lumbar dorsal root ganglia sensory neurons $\left(\boldsymbol{A}-\boldsymbol{C}, \boldsymbol{C}^{\prime}\right)$. Note the lack of colocalization with the neurofilament marker (Nf200) of large neurons and its expression in smaller caliber neurons (arrow). Clusters of small c-Met axons interspaced among large neurofilament labeled axons in the sciatic nerve $(\boldsymbol{D}-\boldsymbol{F})$ and in small dermal nerve bundles in the dermis $\left(\boldsymbol{D}^{\prime}, \boldsymbol{E}^{\prime}\right)$. c-Met was also expressed in epidermal cells $(\boldsymbol{G})$. $\boldsymbol{H}-\mathbf{O}$, Data showing mRNA expression of HGF ligand in skin samples, indicating a large rise in mRNA expression at $48 \mathrm{~h}$ following hair clipping $(\boldsymbol{H}$, ANOVA, $p<0.0001$; posthoc Tukey's 0 vs $48 \mathrm{~h}, p<0.001)$. HGF was expressed in epidermal cells $(I)$, perifollicular cells, and axons in the dermis (I, arrow shows a cluster of hair follicles; $J-L$, arrow shows a dermal axon associated with hair follicles), and in most sensory neurons in the lumbar dorsal root ganglia $(\boldsymbol{M}-\mathbf{0})$, frequently double labeling with neurofilament. Scale bar: $\boldsymbol{A}-\boldsymbol{C}, 50 \mu \mathrm{m} ; \boldsymbol{D}-\boldsymbol{F}, 33 \mu \mathrm{m} ; \boldsymbol{G}, \boldsymbol{I}, 100$ $\mu \mathrm{m} ; J-L, 21 \mu \mathrm{m} ; M-0,50 \mu \mathrm{M}$.

cytes that are known to eventually denucleate and slough. Similarly, single parent axons provide a source for new axon branches or terminals and may give rise to several daughter branches. It is also noteworthy that epidermal axons lose their supporting Schwann cell relationship once they enter the epidermis, indicating a less mature or stable phenotype within the epidermis. What replaces the trophic support of the Schwann cell once in this new milieu has been uncertain. In this work, we provide evidence that HGF is likely one such source of support, generated by epidermal and follicular cells and acting on local
c-Met receptors both on axons and on neighboring epidermal cells. Moreover, most sensory neurons, large and small, apparently express this growth factor. In vitro, we confirmed the supportive and guidance role of HGF for sensory neurons. Thus, a redundant autocrine loop of support is available for cutaneous axons and their cutaneous epidermal cell neighbors. It is also of interest that the c-Met receptor is preferentially expressed in smaller sensory neurons, those associated with unmyelinated axons that eventually innervate the epidermis.

During peripheral axon regeneration within nerve trunks, critical partnering between activated glial SC processes and new axons is essential to regrowth (Chen et al., 2005; McDonald et al., 2006). Activated SCs upregulate GFAP during this guidance behavior (Cheng and Zochodne, 2000). In the present work, at both $48 \mathrm{~h}$ and $7 \mathrm{~d}$ following clipping, there were also more than tenfold rises in mRNAs for GFAP, a marker of activated glial cells and Schwann cells associated with unmyelinated axons, such as those that eventually innervate the epidermis. Since GFAP may also be expressed in keratinocytes and fibroblasts (Danielyan et al., 2007), the changes in mRNA we observed may have arisen from other sources as well. The morphology of GFAP expression, in concert with axons, however, is highly suggestive of a Schwann cell origin, ending at the dermal-epidermal junction, for at least some of the expression (Ebenezer et al., 2007). The findings indicated that partnership with glial cell activation was a feature of axogenesis and might promote it. Overall, it may also be that the synthesis and elaboration of specific neuron proteins within local regenerating axons (intra-axonal translation) plays a major role in their outgrowth behavior. Recent work, for example, suggests that remodeling axons during regeneration express a range of mRNAs that subserve local translation and protein synthesis (Willis et al., 2005; Willis and Twiss, 2006). Neurofilament, the structural scaffold protein of axons, is one such axonally synthesized protein and we encountered large rises in its mRNA that preceded structural evidence for axon growth.

Similarly, outgrowing axons in the dermis and epidermis express the growth molecule GAP43/B50 at their growth cones, a protein not normally prominent in stable axons (Tetzlaff et al., 1989; Verge et al., 1990; Krekoski et al., 2002). GAP43/B50 serves as an actin-binding protein at the growth cone membrane and its expression is upregulated in both neuronal perikarya and distal outgrowing axons after injury. Botchkarev and colleagues (1997) provided evidence for the plasticity of dermal axons by their expression of GAP43/B50 in adolescent mice during hair follicle 


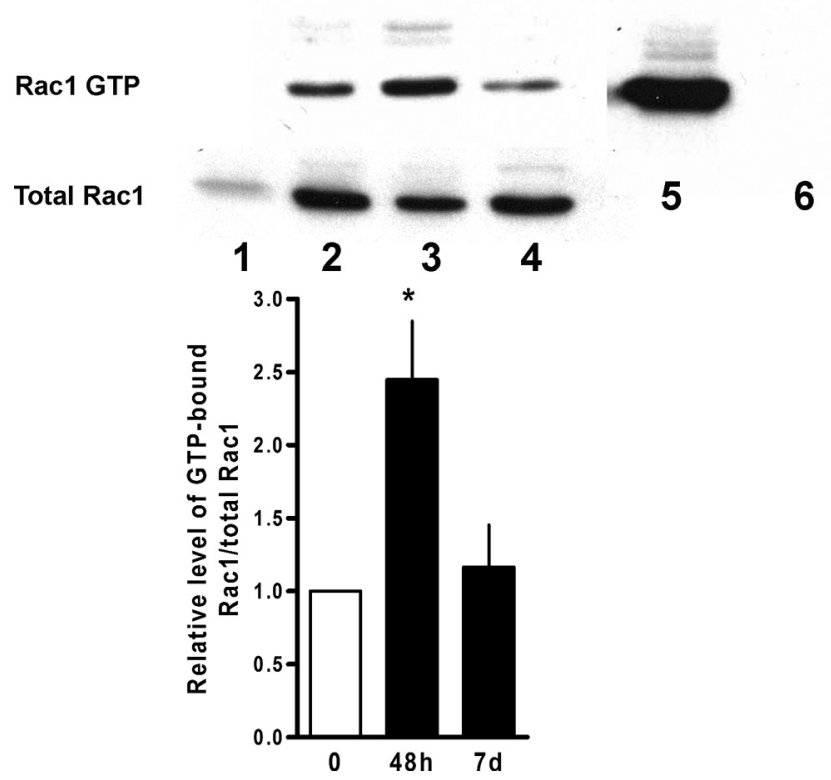

Figure 6. Rac1 is activated by noninvasive hair clipping. Pull-down assays showing activated Rac1 and total Rac1. Lane 1 is a molecular marker ( $20 \mathrm{kDa}$ ). Lane 2 is from skin immediately after clipping, lane 3 at $48 \mathrm{~h}$ following hair clipping, and lane 4 at $7 \mathrm{~d}$ following hair clipping. Lane 5 is a positive control (from the manufacturer) and lane 6 is a negative control. Protein from each band was harvested from four mice (two back skin biopsy samples for each mouse), repeated three times in separate groups of mice. Quantitation identifies a significant rise in the ratio of activated Rac1 to total Rac1 at $48 \mathrm{~h}$ following shaving (ANOVA, $p=0.02$; post hoc Tukey's 0 vs $48 \mathrm{~h}, p<0.05$ ).

cycling. During depilation-induced early anagen (active phase of hair growth cycle) hair follicle growth, an invasive stimulus that removes the full hair shaft, there was a rise in follicular innervation. Depilation leads to anagen hair follicle development (Zhou et al., 2006). Similarly, hair clipping can induce anagen hair follicle cycling and it is likely the responses in innervation we observed are related (Botchkarev et al., 1997; Hendrix and Peters, 2007). Adult mice, however, do not have synchronous waves of hair follicle cycling and it is likely that our preclipping control samples had a large proportion of hair follicles in telogen (quiescent phase of hair growth cycle), but nonetheless showed evidence of axon plasticity (Müller-Röver et al., 2001; Botchkarev and Paus, 2003). Overall, we note that these features of axon plasticity were also upregulated by much less invasive stimulation-simple hair clipping that did not unroot the full hair shaft or disrupt the underlying skin. It is conceivable that gentle skin rubbing during hair clipping, associated with very mild inflammation, may be enough to alter plasticity. An inflammatory response that was prominent enough to be associated with widespread release of neurotrophic cytokines capable of altering innervation however, seems unlikely. A control experiment involving rubbing the skin without hair truncation did not generate epidermal plasticity.

We believe that the mechanism of this unexpected wave of cutaneous and axon plasticity after clipping involves diffuse activation of epidermal cells. How the skin senses hair clipping is uncertain but may arise from a mechanical signal, or the addition or removal of a growth-related signal from the hair shaft. We suspect this signal originates in the follicular area, which newly acquires the thy-1 YFP transgene, then spreads to epidermal cells diffusely, which similarly become activated, a response also previously reported by Pan and Sanes (2004) after skin wounding.
Electronic coupling, described between epidermal cells through calcium waves and documented in keratinocytes cocultured with sensory neurons (Koizumi et al., 2004), may transmit an activation signal rapidly. By 48 h, we observed diffuse activation of epidermal and perifollicular cells and a rise in the density of nucleated superficial epidermal cells. This was also consistent with large rises in mRNA for EGF, a potent ligand for epidermal cells. Similarly, there was evidence of heightened Sox 2 mRNA expression and a similar trend in other stem cell markers, indicating possible follicular activation, in keeping with the proliferative state. Sox2 is expressed in neural stem cells, Schwann cell precursors, and is essential for neuroectoderm formation (Avilion et al., 2003; Hong and Saint-Jeannet, 2005; Wegner and Stolt, 2005). Although Sox 2 protein was confirmed in skin samples by immunoblots, we were unable to confirm an overall rise in the protein concurrent with the mRNA changes, perhaps related to an inability to selectively measure its content strictly in the perifollicular space (Cheung and Briscoe, 2003; Wegner and Stolt, 2005; Biernaskie et al., 2009). The cells expressing Sox 2 and Sox9 appeared to overlap with the bulge stem cells of hair follicles and the dermal niches for skin-derived precursor cells (Cotsarelis, 2006; Ohyama, 2007; Fernandes et al., 2008).

We believe that HGF is an ideal candidate to provide linked epidermal, follicular, and axon plasticity. In cutaneous wounds, its neutralization retards healing (Yoshida et al., 2003; Chmielowiec et al., 2007). Moreover, it may be a strong candidate for promoting perifollicular axon growth and for attracting or maintaining the epidermal complement of axons residing without a supporting glial cell. We confirm its role, described by others (Maina et al., 1997; Funakoshi and Nakamura, 2001; Zhang and Vande Woude, 2003; Kato et al., 2005; Sanford et al., 2008), as an attractant and trophic molecule using HGF impregnated stripes. HGF, a pleiotrophic growth factor, was expressed by epidermal and follicular cells poised to attract axons to associate with them. HGF also appears to have autocrine capability, since its receptor, c-Met, was expressed on similar cutaneous cells. Importantly, c-Met was expressed on the very population of unmyelinated axons, originating from smaller caliber ganglia neurons, that innervate the epidermis. It may not be necessary for these receptors to be expressed in the very distant axon terminals, since ligation of receptors on dermal axons may be sufficient to support their penetration into the nearby epidermis. Also, the demonstration of specific proteins and peptides within fine epidermal axons is notoriously difficult. For example, although early anatomical preparations identified the presence of epidermal axons, immunohistochemical analysis did not occur until more recently (Kennedy and WendelschaferCrabb, 1993; Johansson, 1995).

Overall, it is interesting to note that a wide complement of sensory neurons, including large ones likely only to support larger myelinated dermal axons, expressed HGF. Its expression was more widespread than that of its receptor, another feature of the complexity of this system. It may be that HGF has an autocrine and paracrine role in which liberation of the growth factor either in the skin or the ganglia supports neurons expressing c-Met. Yet another important role, particularly in this milieu, is the known support HGF can provide directly to glial Schwann cells that support axon outgrowth (Krasnoselsky et al., 1994). These may be features in the full range of probable interactions we did not further explore, but could, for example, be addressed in sensory neuron-epidermal cocultures, provided they are designed to reflect the adult milieu. 
We recognize that other cutaneous signaling mechanisms likely link epidermal cells, follicular cells, and axons that are not fully addressed here. EGF may be an additional candidate for a growth factor capable of activating both epidermal and neural elements (Landreth, 2006). Several other classical neuronal growth factor mRNAs did not appreciably rise during the type of activation we studied, but we cannot exclude a primary, complementary, or facilitatory role for them. In particular, Paus and colleagues (Botchkarev et al., 1997; Botchkarev and Paus, 2003) have carefully characterized such interactions. The events we studied were coupled with an early rise in activated cutaneous Rac1, a downstream effector of HGF signaling (Zhang and Vande Woude, 2003) that is a critical pathway in skin and neuron plasticity (Chmielowiec et al., 2007). At least two downstream pathways from $\mathrm{HGF}-\mathrm{c}-\mathrm{Met}$ activation are possible, one involving Rac1 involved in morphogenesis, including axon actin remodeling, and another pathway independent of Racl involving Ras and promoting proliferation (Zhang and Vande Woude, 2003). We also cannot exclude the possibility that other activators contributed toward Racl activation beyond the HGF pathway.

The range of other noninvasive stimuli that might alter axogenesis or the molecular expression of normal cutaneous axons is interesting to contemplate. Habituation to different climates, shaving frequency, or the use of cosmetic skin preparations in humans might alter the normal innervation of the skin. Whether analogous plasticity can be generated noninvasively in glabrous skin is uncertain. Finally, it is intriguing to speculate whether restless and dynamic axon behavior, in conjunction with local tissue turnover, is a feature of most tissues innervated by sensory axons.

\section{References}

Avilion AA, Nicolis SK, Pevny LH, Perez L, Vivian N, Lovell-Badge R (2003) Multipotent cell lineages in early mouse development depend on SOX2 function. Genes Dev 17:126-140.

Biernaskie JA, McKenzie IA, Toma JG, Miller FD (2006) Isolation of skinderived precursors (SKPs) and differentiation and enrichment of their Schwann cell progeny. Nat Protoc 1:2803-2812.

Biernaskie J, Paris M, Morozova O, Fagan BM, Marra M, Pevny L, Miller FD (2009) SKPs Derive from hair follicle precursors and exhibit properties of adult dermal stem cells. Cell Stem Cell 5:610-623.

Botchkarev VA, Paus R (2003) Molecular biology of hair morphogenesis: development and cycling. J Exp Zool B Mol Dev Evol 298:164-180.

Botchkarev VA, Eichmüller S, Johansson O, Paus R (1997) Hair cycledependent plasticity of skin and hair follicle innervation in normal murine skin. J Comp Neurol 386:379-395.

Brussee V, Guo G, Dong Y, Cheng C, Martinez JA, Smith D, Glazner GW, Fernyhough P, Zochodne DW (2008) Distal degenerative sensory neuropathy in a long term type 2 diabetes rat model. Diabetes 57:1664-1673.

Chen YY, McDonald D, Cheng C, Magnowski B, Durand J, Zochodne DW (2005) Axon and Schwann cell partnership during nerve regrowth. J Neuropathol Exp Neurol 64:613-622.

Cheng C, Zochodne DW (2002) In vivo proliferation, migration and phenotypic changes of Schwann cells in the presence of myelinated fibers. Neuroscience 115:321-329.

Cheng C, Webber CA, Wang J, Xu Y, Martinez JA, Liu WQ, McDonald D, Guo GF, Nguyen MD, Zochodne DW (2008) Activated RHOA and peripheral axon regeneration. Exp Neurol 212:358-369.

Cheung M, Briscoe J (2003) Neural crest development is regulated by the transcription factor Sox9. Development 130:5681-5693.

Chmielowiec J, Borowiak M, Morkel M, Stradal T, Munz B, Werner S, Wehland J, Birchmeier C, Birchmeier W (2007) c-Met is essential for wound healing in the skin. J Cell Biol 177:151-162.

Cotsarelis G (2006) Epithelial stem cells: a folliculocentric view. J Invest Dermatol 126:1459-1468.

Danielyan L, Tolstonog G, Traub P, Salvetter J, Gleiter CH, Reisig D, Gebhardt R, Buniatian GH (2007) Colocalization of glial fibrillary acidic protein, metallothionein, and MHC II in human, rat, NOD/SCID, and nude mouse skin keratinocytes and fibroblasts 4. J Invest Dermatol 127:555-563.

David MD, Yeramian A, Duñach M, Llovera M, Cantí C, de Herreros AG, Comella JX, Herreros J (2008) Signalling by neurotrophins and hepatocyte growth factor regulates axon morphogenesis by differential betacatenin phosphorylation. J Cell Sci 121:2718-2730.

Ebenezer GJ, McArthur JC, Thomas D, Murinson B, Hauer P, Polydefkis M, Griffin JW (2007) Denervation of skin in neuropathies: the sequence of axonal and Schwann cell changes in skin biopsies 2. Brain 130:2703-2714.

Fantini F, Johansson O (1992) Expression of growth-associated protein 43 and nerve growth factor receptor in human skin: a comparative immunohistochemical investigation 3. J Invest Dermatol 99:734-742.

Feng G, Mellor RH, Bernstein M, Keller-Peck C, Nguyen QT, Wallace M, Nerbonne JM, Lichtman JW, Sanes JR (2000) Imaging neuronal subsets in transgenic mice expressing multiple spectral variants of GFP. Neuron 28:41-51.

Fernandes KJ, McKenzie IA, Mill P, Smith KM, Akhavan M, Barnabé-Heider F, Biernaskie J, Junek A, Kobayashi NR, Toma JG, Kaplan DR, Labosky PA, Rafuse V, Hui CC, Miller FD (2004) A dermal niche for multipotent adult skin-derived precursor cells. Nat Cell Biol 6:1082-1093.

Fernandes KJ, Toma JG, Miller FD (2008) Multipotent skin-derived precursors: adult neural crest-related precursors with therapeutic potential. Philos Trans R Soc Lond B Biol Sci 363:185-198.

Funakoshi H, Nakamura T (2001) Identification of HGF-like protein as a novel neurotrophic factor for avian dorsal root ganglion sensory neurons 26. Biochem Biophys Res Commun 283:606-612.

Hashimoto N, Yamanaka H, Fukuoka T, Obata K, Mashimo T, Noguchi K (2001) Expression of hepatocyte growth factor in primary sensory neurons of adult rats 1. Brain Res Mol Brain Res 97:83-88.

Henderson J, Terenghi G, McGrouther DA, Ferguson MW (2006) The reinnervation pattern of wounds and scars may explain their sensory symptoms. J Plast Reconstr Aesthet Surg 59:942-950.

Hendrix S, Peters EM (2007) Neuronal plasticity and neuroregeneration in the skin: the role of inflammation. J Neuroimmunol 184:113-126.

Hendrix S, Picker B, Liezmann C, Peters EM (2008) Skin and hair follicle innervation in experimental models: a guide for the exact and reproducible evaluation of neuronal plasticity. Exp Dermatol 17:214-227.

Herrmann DN, Griffin JW, Hauer P, Cornblath DR, McArthur JC (1999) Epidermal nerve fiber density and sural nerve morphometry in peripheral neuropathies. Neurology 53:1634-1640.

Holland NR, Stocks A, Hauer P, Cornblath DR, Griffin JW, McArthur JC (1997) Intraepidermal nerve fiber density in patients with painful sensory neuropathy. Neurology 48:708-711.

Hong CS, Saint-Jeannet JP (2005) Sox proteins and neural crest development. Semin Cell Dev Biol 16:694-703.

Johansson O (1995) The innervation of the human epidermis. J Neurol Sci 130:228.

Kato N, Nemoto K, Nakanishi K, Morishita R, Kaneda Y, Uenoyama M, Ikeda T, Fujikawa K (2005) Nonviral HVJ (hemagglutinating virus of Japan) liposome-mediated retrograde gene transfer of human hepatocyte growth factor into rat nervous system promotes functional and histological recovery of the crushed nerve 3. Neurosci Res 52:299-310.

Kennedy JM, Zochodne DW (2005) Experimental diabetic neuropathy and spontaneous recovery: is there irreparable damage? Diabetes 54:830-837.

Kennedy WR, Wendelschafer-Crabb G (1993) The innervation of human epidermis. J Neurol Sci 115:184-190.

Koizumi S, Fujishita K, Inoue K, Shigemoto-Mogami Y, Tsuda M, Inoue K (2004) $\mathrm{Ca} 2+$ waves in keratinocytes are transmitted to sensory neurons: the involvement of extracellular ATP and P2Y2 receptor activation. Biochem J 380:329-338.

Krasnoselsky A, Massay MJ, DeFrances MC, Michalopoulos G, Zarnegar R, Ratner N (1994) Hepatocyte growth factor is a mitogen for Schwann cells and is present in neurofibromas. J Neurosci 14:7284-7290.

Krekoski CA, Neubauer D, Graham JB, Muir D (2002) Metalloproteinasedependent predegeneration in vitro enhances axonal regeneration within acellular peripheral nerve grafts. J Neurosci 22:10408-10415.

Landreth GE (2006) Growth factors. In: Basic neurochemistry (Siegel GJ, Albers RW, Brady ST, Price DL, eds), pp 471-484. New York: Academic.

Lauria G, Cornblath DR, Johansson O, McArthur JC, Mellgren SI, Nolano M, Rosenberg N, Sommer C (2005) EFNS guidelines on the use of skin biopsy in the diagnosis of peripheral neuropathy. Eur J Neurol 12:747-758. 
Lim YS, McLaughlin T, Sung TC, Santiago A, Lee KF, O’Leary DD (2008) p75(NTR) mediates ephrin-A reverse signaling required for axon repulsion and mapping. Neuron 59:746-758.

Maina F, Klein R (1999) Hepatocyte growth factor, a versatile signal for developing neurons. Nat Neurosci 2:213-217.

Maina F, Hilton MC, Ponzetto C, Davies AM, Klein R (1997) Met receptor signaling is required for sensory nerve development and HGF promotes axonal growth and survival of sensory neurons 2. Genes Dev 11:33413350 .

McDonald D, Cheng C, Chen Y, Zochodne D (2006) Early events of peripheral nerve regeneration. Neuron Glia Biology 2:139-147.

Müller-Röver S, Handjiski B, van der Veen C, Eichmüller S, Foitzik K, McKay IA, Stenn KS, Paus R (2001) A comprehensive guide for the accurate classification of murine hair follicles in distinct hair cycle stages. J Invest Dermatol 117:3-15.

Ohyama M (2007) Hair follicle bulge: a fascinating reservoir of epithelial stem cells. J Dermatol Sci 46:81-89.

Pan YA, Sanes JR (2004) Non-invasive visualization of epidermal responses to injury using a fluorescent transgenic reporter. J Invest Dermatol 123:888-891.

Piper M, Holt C (2004) RNA translation in axons. Annu Rev Cell Dev Biol 20:505-523.

Rashid T, Upton AL, Blentic A, Ciossek T, Knöll B, Thompson ID, Drescher U (2005) Opposing gradients of ephrin-As and EphA7 in the superior colliculus are essential for topographic mapping in the mammalian visual system 1. Neuron 47:57-69.

Sanford SD, Gatlin JC, Hökfelt T, Pfenninger KH (2008) Growth cone responses to growth and chemotropic factors 2. Eur J Neurosci 28:268-278.

Tetzlaff W, Zwiers H, Lederis K, Cassar L, Bisby MA (1989) Axonal trans- port and localization of B-50/GAP-43-like immunoreactivity in regenerating sciatic and facial nerves of the rat. J Neurosci 9:1303-1313.

Toma JG, McKenzie IA, Bagli D, Miller FD (2005) Isolation and characterization of multipotent skin-derived precursors from human skin. Stem Cells 23:727-737

Verge VM, Tetzlaff W, Richardson PM, Bisby MA (1990) Correlation between GAP43 and nerve growth factor receptors in rat sensory neurons. J Neurosci 10:926-934.

Wegner M, Stolt CC (2005) From stem cells to neurons and glia: a Soxist's view of neural development. Trends Neurosci 28:583-588.

Whitbread LA, Powell BC (1998) Expression of the intermediate filament keratin gene, K15, in the basal cell layers of epithelia and the hair follicle. Exp Cell Res 244:448-459.

Willis DE, Twiss JL (2006) The evolving roles of axonally synthesized proteins in regeneration. Curr Opin Neurobiol 16:111-118.

Willis D, Li KW, Zheng JQ, Chang JH, Smit A, Kelly T, Merianda TT, Sylvester J, van Minnen J, Twiss JL (2005) Differential transport and local translation of cytoskeletal, injury-response, and neurodegeneration protein mRNAs in axons. J Neurosci 25:778-791.

Yoshida S, Yamaguchi Y, Itami S, Yoshikawa K, Tabata Y, Matsumoto K, Nakamura T (2003) Neutralization of hepatocyte growth factor leads to retarded cutaneous wound healing associated with decreased neovascularization and granulation tissue formation. J Invest Dermatol 120:335343.

Zhang YW, Vande Woude GF (2003) HGF/SF-met signaling in the control of branching morphogenesis and invasion. J Cell Biochem 88:408-417.

Zhou Z, Kawana S, Aoki E, Katayama M, Nagano M, Suzuki H (2006) Dynamic changes in nerve growth factor and substance $\mathrm{P}$ in the murine hair cycle induced by depilation. J Dermatol 33:833-841. 